\title{
RELATIVE CONTRIBUTIONS OF INTRACORTICAL AND THALAMO-CORTICAL PROCESSES IN THE GENERATION OF ALPHA RHYTHMS, REVEALED BY PARTIAL COHERENCE ANALYSIS
}

\author{
F.H. LOPES DA SILVA ${ }^{1}$, J.E. VOS ${ }^{2}$, J. MOOIBROEK ${ }^{2}$ and A. VAN ROTTERDAM ${ }^{1}$ \\ ${ }^{1}$ Brain Research Department, Institute of Medical Physics TNO, Da Costakade 45, Utrecht, and ${ }^{2}$ Department of \\ Developmental Neurology, University of Groningen, Groningen (The Netherlands)
}

(Accepted for publication: June 24, 1980)

A good deal of electroencephalographic research in man pertains to the alpha rhythms as recorded from the scalp. In order to understand the neurophysiology of alpha rhythms one has, however, to resort to studies in other species which may offer an experimental model of the human alpha rhythm, for example cat (Lanoir and Cordeau 1970; Lanoir 1972; Rougeul et al. 1974) and dog (Storm van Leeuwen et al. 1967; Lopes da Silva et al. 1973).

Previous studies (Storm van Leeuwen et al. 1967; Lopes da Silva et al. 1973) have revealed that intracortical coherences are in general larger than any thalamo-cortical coherence measured in the same dog. This entails the following question: are these large intracortical coherences exclusively due to an intracortical process independent of thalamic sources, or not? In other words, the question is to measure the amount of thalamic influence on the large intracortical coherences. One possible way to solve this problem would be to measure the amount of intracortical coherence before and after making a thalamic lesion. This method, however, could lead to a radical change of the whole physiological state responsible for the generation of the alpha rhythm and therefore it would not be suited to the purpose. An alternative approach is by way of a signal-analytical technique by means of which a sort of 'theoretical thalamic deafferentation' can be achieved. This technique resorts to the computation of partial coherence functions. Such functions have been applied already in a few cases to neurophysiological problems such as that of spread of epileptiform activity (Gersch and Goddard 1969), of the organization of EEG during development (Vos et al. 1977) and the analysis of seizure patterns within the cortex (Rappelsberger et al. 1979). We report here some of the results obtained with this method. A more extensive report is published elsewhere (Lopes da Silva et al. 1980).

\section{Theoretical considerations}

Computing partial coherences implies first eliminating from each of the two signals of a pair (e.g. two cortical signals) that part that can be considered as being determined by, or predictable on the basis of, a third signal (e.g. a thalamic signal). Let us consider the following cases: we record alpha rhythms from two cortical areas and one thalamic area; the former are the signals $\mathrm{C}_{1}$ and $\mathrm{C}_{2}$; the latter is the signal $t_{1}$. We assume that $C_{1}$ and $C_{2}$ may contain contributions which are determined by $t_{1}$, and for which linear least-square predictions can be computed based on the knowledge of th $\mathrm{t}_{1}$ and on the cross power spectra between both $\mathrm{th}_{1}$ and $\mathrm{C}_{1}$, and $\mathrm{th}_{1}$ and $\mathrm{C}_{2}$. When we correct $\mathrm{C}_{1}$ and $\mathrm{C}_{2}$ for these 'predictable' contributions we can compute the 
(partial) coherence between the residual signals as follows:

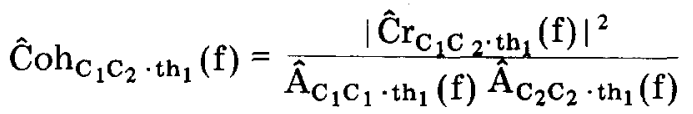

where the residual spectra are defined as follows:

$$
\begin{aligned}
& \hat{\mathrm{C}} \mathrm{r}_{\mathrm{C}_{1} \mathrm{C}_{2} \cdot \mathrm{th}_{1}} \text { (f) } \\
& \quad=\hat{\mathrm{C}} \mathrm{r}_{\mathrm{C}_{1} \mathrm{C}_{2}} \text { (f) }\left[1-\frac{\hat{\mathrm{C}} \mathrm{r}_{\mathrm{C}_{1} \mathrm{th}_{1}} \text { (f) } \hat{\mathrm{C}} \mathrm{r}_{\mathrm{C}_{2} \text { th }}(\mathrm{f})}{\hat{\mathrm{A}}_{\mathrm{th}_{1} \mathrm{th}_{1}}(\mathrm{f}) \hat{\mathrm{C}} \mathrm{r}_{\mathrm{C}_{1} \mathrm{C}_{2}}(\mathrm{f})}\right]
\end{aligned}
$$

and

$\hat{A}_{C_{1} C_{1} \cdot t_{1}}(f)=\hat{A}_{C_{1} C_{1}}(f)\left[1-\hat{C o h}_{C_{1} t_{1}}(f)\right]$

and

$\hat{A}_{C_{2} C_{2} \cdot \operatorname{th}_{1}}(f)=\hat{A}_{C_{2} C_{2}}(f)\left[1-\hat{C o h}_{C_{2} \operatorname{th}_{1}}(f)\right]$

where $\hat{C} r$ is the estimated cross power spectra, $\hat{\mathrm{A}}$ is the estimated autospectra and $\hat{\mathrm{Coh}}_{\mathrm{C}_{1} \mathrm{th}_{1}}$, $\hat{\mathrm{Coh}}_{\mathrm{C}_{2} \mathrm{th}_{1}}$ are the estimated magnitudesquared coherences, called coherences in the remainder of this paper. The estimated coherence between $C_{1}$ and $C_{2}$ partialized on th $h_{1}$ is given by $\mathrm{Coh}_{\mathrm{C}_{1} \mathrm{C}_{2}} \cdot \operatorname{th}_{1}(\mathrm{f})$.

\section{Material and methods}

$\mathrm{Th} 3$ investigation was done in the same dogs as used before (Lopes da Silva et al. 1973). The relevant epochs of the EEGs of thalamic and cortical sites recorded for the previcus study had been stored on digital tape and therefore could be used again for computing partial coherence functions. In summary, we used records of alpha rhythms obtained by way of two types of electrode: (a) bundles of $3-7$ wires (100 $\mu$ m diameter) insulated to 0.5 (thalamic sites) or $1 \mathrm{~mm}$ (cortical sites) from the tip; (b) sheets of wires with uninsulated surfaces of $0.15-0.20 \mathrm{~mm}$ which were embedded in a polyethylene sheet less than $0.5 \mathrm{~mm}$ thick. The bundles by way of which alpha rhythms were recorded, were inserted in the marginal gyrus (dog $C)$ and in the lateral geniculate nucleus (LGN) and pulvinar nucleus. The sheets were placed under the dura either over the occipital marginal gyrus or over the mesial cortex above the calcarine region. The positions of the electrodes were confirmed post mortem by histological examination (sections of the brain $15 \mu \mathrm{m}$ thick stained by Klüver or Nissl methods). Derivations were made in general against one common electrode, a stainless steel pin placed in the frontal bone at the level of the frontal sinus. As some electrodes were placed in areas free of alpha rhythms the degrees of 'indifference' of the common electrode as regards the phenomenon being studied could be determined. Recording was by means of a 16channel radiotelemetry system (Storm van Leeuwen and Kamp 1969). The signals were further amplified by a 16-channel EEG Offner-Beckman dynograph and stored on magnetic tape (EMI) simultaneously with a time code. The epochs of EEG used for analysis were selected on the basis of the presence of alpha rhythms. They were digitized by way of an 8-channel analogue-to-digital converter. The signals were passed by anti-aliasing filters with a band between 0.5 and $30 \mathrm{c} / \mathrm{sec}$. The sampling frequency was $80 / \mathrm{sec}$. Analysed epochs consisted either of 1024 (duration $12.8 \mathrm{sec}$ ) or of 256 sample points (duration $3.2 \mathrm{sec}$ ). The digitized signals were stored on DEC tape (PDP 9 computer). The same tapes as used in the previous study were analysed again by way of the PDP 15 computer at the University of Groningen, using the partial coherence program developed there (Vos et al. 1977).

The statistical evaluation of the results was done as follows: in order to improve the reliability of the estimates of spectra and coherences we performed ensemble averaging. Coherence functions were treated statistically by way of the z-transformation in a similar way to that usually employed for the correlation coefficient. In this way the square root of the coherence function (i.e. of the coherence as defined by eq. 1) was first taken and then the $\mathrm{z}$-transform was computed. The corresponding standard deviation was calculated using the formula: $1 / \sqrt{\mathrm{N}-3}$ (Dixon and Mas- 
sey 1957, p. 201) where $\mathrm{N}$ was 80 for the cases of $\operatorname{dogs} D$ and $R$, and 40 for $\operatorname{dog} C$. In order to quantify in an explicit way the results obtained by using partial coherences we decided to formulate these results as the difference between the ordinary coherence for a particular frequency and the corresponding partial coherence; these differences were then expressed in terms of the standard deviation (S.D.) of the ordinary coherence. Moreover we tested whether the z-transformed partial coherence values differed significantly from the corresponding values of the ordinary coherence using the $t$ test. $t=\left[\left(\overline{\mathbf{x}}_{1}-\overline{\mathrm{x}}_{2}\right) /\right.$ $(\sqrt{2 / \mathrm{N}} \times$ S.D. $)]$ should be $>2.358$ in order to accept a difference between 2 means as significant at $P<0.01 \quad(\mathrm{df}=2 \times 80-2$ for the cases of dogs $D$ and $R$, and $d f=2 \times 40-2$ for the case of $\operatorname{dog} C$ ). In our case $\bar{x}_{1}-\bar{x}_{2}=\Delta z$; for the cases where $\mathrm{N}=80$ a value $\Delta \mathrm{z}>0.372$ S.D. should be reached in order for the difference to be accepted as significant at $P<0.01$; for the case where $N=40$ it should be $\Delta z>$ 0.527 S.D.

\section{Results}

Effects of eliminating thalamic components on cortico-cortical coherences in the alpha band

For most pairs of cortical signals investigated in all dogs there was a significant $(P<$ 0.01 ) decrease of the coherence after partialization, indicating that the thalamic signal contributed to the alpha rhythms recorded from both cortical sites, as shown in Fig. 1 .

A remarkable feature of the results obtained by partialization was that the effect of removing the influence of the LGN signals on cortico-cortical coherences was small, although significant, in all cases investigated. For dog $\mathrm{D}$ the maximal decrease in coherence was $1.8 \times \mathrm{S} . \mathrm{D}$.; for $\operatorname{dog} \mathrm{R}$ it was $2 \mathrm{~S} . \mathrm{D}$. and for $\operatorname{dog} C$ it was 1 S.D. In contrast, the effect of eliminating the influence of the signal from the pulvinar was, in all cases, much larger than that of removing the LGN signal, as also shown in Table I and Fig. 1. From this it can be concluded that the extent of the influence of the pulvinar over the cortical alpha rhythms was much greater than that of the LGN.

One point to be examined is the value of the remaining cortico-cortical coherence after partialization on a thalamic signal. In this case two groups of results may be distinguished: (a) those where the partial coherence remained appreciable and (b) those where it decreased to negligible values. Most cases studied were of the former type; the latter cases were all combinations including the marginal gyrus and one mesial cortical signal (D8, D15; D8, D17) in dog D when the influence of the pulvinar (D27) was eliminated (Table I). These findings lead to the following conclusions: although a remarkable effect of thalamic signals on the degree of coherence between cortical alpha rhythms could be demonstrated, there must exist other factors which are responsible for the remaining large values of intracortical partial coherences; in some cases, however, such as between the alpha rhythms of marginal gyrus and mesial cortex sites in $\operatorname{dog} \mathrm{D}$, the coherence in the alpha band was determined almost exclusively by the influence of a thalamic signal, that of the pulvinar (D27). This experimental result is shown in Fig. 1 ; in this figure it can be seen that by eliminating the influence of D27 the coherence between D8 (marginal gyrus) and D15 (mesial cortex) in the alpha band (12-13 $\mathrm{Hz}$ ) decreased to negligible values; approximately the same happened by eliminating the influence of the signal recorded from neighbouring sites at the mesial cortex (D13 or D17). However, there was a difference between the partial coherence components at a frequency double that of the alpha band: the effect of partialization by way of the thalamic signal (D27) was negligible at this frequency whereas that of partialization by way of the mesial cortex signals (D13 or D17) was appreciable, mainly that of $\mathrm{D} 17$. This dissociation of frequency components by way of partialization is an indication that different 
A

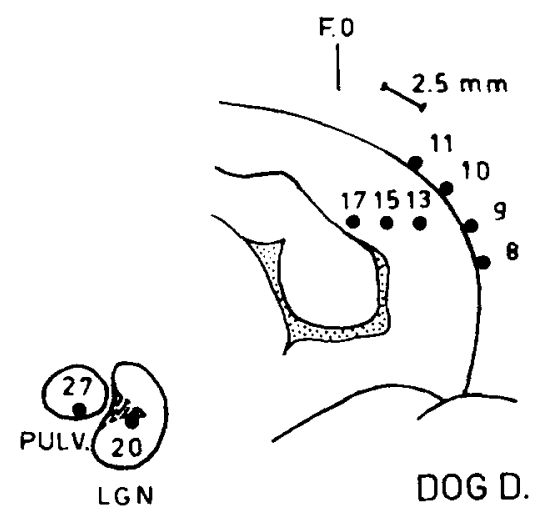

1ST ROW: ORDINARY COHERENCE 1: D8 $\times 5:$ D1S

OTHER ROWS:

PARTIAL COHERENCES HHERE THE 3Nd SIGNAL IS AS INDICATED BELOW

LGN
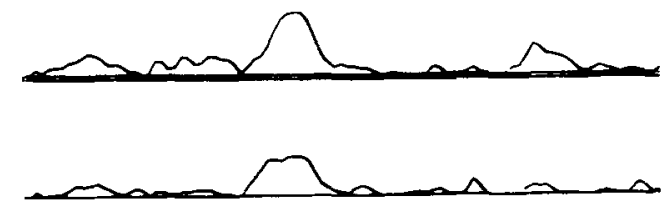

2: D9

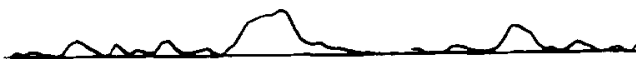

3: D11

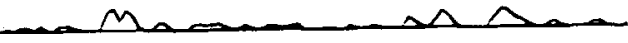

4: D13

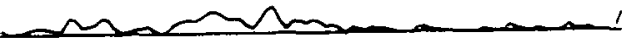

6: D17

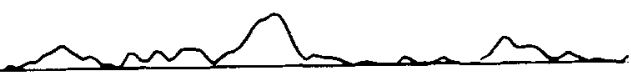

$7: \mathrm{D} 20$

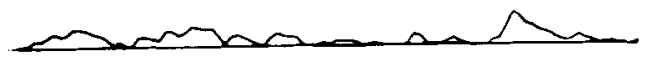

8: 027

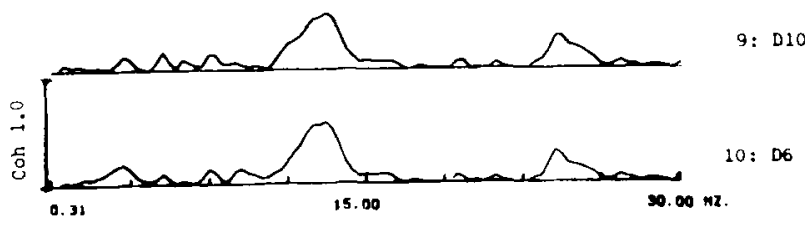

B

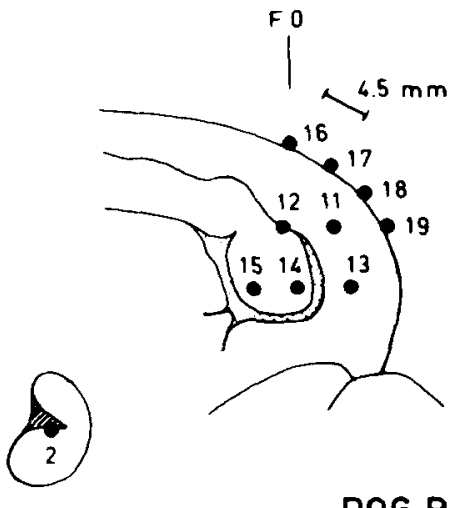

LGN

DOG R.

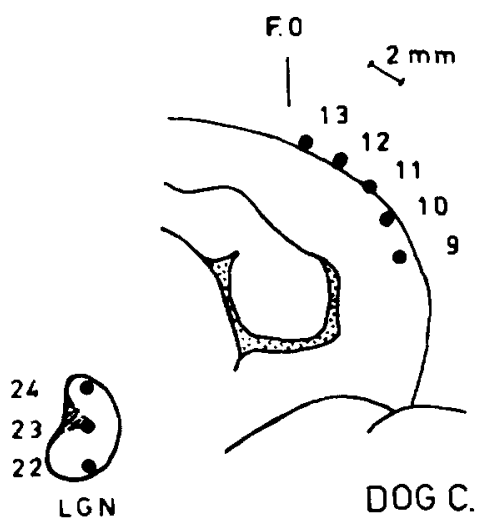

Fig. 1. A: $\operatorname{dog}$ D: ordinary and partial coherences for a number of electrode combinations, the placements of which are indicated on the left. The ordinary coherence between D8 and D 15 is shown in the first trace. The effect of partialization using other cortical or thalamic signals is shown in other traces (D9, D11, D13, D17, D10); these are from the ipsilateral cortex and D6 from the contralateral cortex; D20 from LGN and D27 from pulvinar. Note the large decrease in coherence, mainly within the alpha band, from partialization using other cortical signals (D13 and D17) and also D27. B: electrode placements for dogs R and C (see Table I). 
TABLE I

Summary of the effect on cortico-cortical coherences of thalamic signals in the alpha band (for electrode placements see Fig. 1).

\begin{tabular}{|c|c|c|c|c|c|}
\hline \multirow{3}{*}{$\begin{array}{l}\text { Signals } \\
\text { from } \\
\text { electrodes }\end{array}$} & \multicolumn{3}{|c|}{ Ordinary coherences (Coh) } & \multirow{2}{*}{\multicolumn{2}{|c|}{$\begin{array}{l}\text { Difference }(\Delta z) \text { between the } \mathrm{z} \text {-transformed }(\mathrm{Coh})^{1 / 2} \\
\text { after partialization on the signal recorded from } \\
\text { thalamic sites and the } \mathrm{Z}_{\mathrm{Coh}}: \Delta \mathrm{z}=\mathrm{q} \times \mathrm{S} \text {.D. }\end{array}$}} \\
\hline & \multirow{2}{*}{$\begin{array}{l}\text { Frequency } \\
(\mathrm{Hz})\end{array}$} & \multirow[t]{2}{*}{ Coh } & \multirow{2}{*}{$\begin{array}{l}\mathrm{Z} \text {-trans- } \\
\text { formed } \\
(\mathrm{Coh})^{1 / 2} \\
=\mathrm{Z}_{\mathrm{Coh}}\end{array}$} & & \\
\hline & & & & $\begin{array}{l}\text { D27 (pulvinar) } \\
\text { q }\end{array}$ & $\begin{array}{l}\mathrm{D} 20(\mathrm{LGN}) \\
\mathrm{q}\end{array}$ \\
\hline $\mathrm{D} 17, \mathrm{D} 15$ & 12.2 & 0.94 & 2.09 & -5.5 & -1.8 \\
\hline $\mathrm{D} 15, \mathrm{D} 13$ & 12.2 & 0.96 & 2.30 & -5.6 & -1.2 \\
\hline $\mathrm{D} 8, \mathrm{D} 9$ & 12.2 & 0.70 & 1.22 & -2.4 & -0.6 \\
\hline $\mathrm{D} 9, \mathrm{D} 11$ & 12.2 & 0.57 & 0.97 & -1.2 & n.s. \\
\hline $\mathrm{D} 8, \mathrm{D} 15$ & 12.2 & 0.46 & 0.83 & -8.3 & -1.8 \\
\hline $\mathrm{D} 8, \mathrm{D} 17$ & 12.2 & 0.42 & 0.78 & -7.8 & -1.8 \\
\hline $\mathrm{D9}, \mathrm{D} 13$ & 12.2 & 0.29 & 0.60 & -4.6 & -1.0 \\
\hline $\mathrm{D} 11, \mathrm{D} 13$ & 12.5 & 0.30 & 0.62 & -2.9 & +0.8 \\
\hline \multirow[t]{3}{*}{$\mathrm{D} 8, \mathrm{D} 6$} & 11.9 & 0.17 & 0.42 & -2.7 & -0.4 \\
\hline & & & & \multicolumn{2}{|l|}{ R2 (LGN) } \\
\hline & & & & \multicolumn{2}{|l|}{$q$} \\
\hline $\mathbf{R} 12, \mathbf{R} 11$ & 12.5 & 0.64 & 1.10 & \multicolumn{2}{|l|}{ n.s. } \\
\hline $\mathbf{R} 11, \mathbf{R} 13$ & 12.5 & 0.46 & 0.83 & \multicolumn{2}{|l|}{ n.s. } \\
\hline $\mathrm{R} 14, \mathrm{R} 13$ & 12.5 & 0.86 & 1.66 & \multicolumn{2}{|l|}{-0.7} \\
\hline $\mathrm{R} 14, \mathrm{R} 12$ & 12.7 & 0.80 & 1.42 & \multicolumn{2}{|l|}{-0.4} \\
\hline $\mathrm{R} 15, \mathrm{R} 14$ & 12.9 & 0.72 & 1.26 & \multicolumn{2}{|l|}{-0.4} \\
\hline $\mathrm{R} 16, \mathrm{R} 17$ & 12.5 & 0.30 & 0.62 & \multicolumn{2}{|l|}{-2.0} \\
\hline $\mathrm{R} 17, \mathrm{R} 18$ & 12.5 & 0.38 & 0.73 & \multicolumn{2}{|l|}{-1.0} \\
\hline $\mathrm{R} 18, \mathrm{R} 19$ & 12.6 & 0.40 & 0.74 & \multicolumn{2}{|l|}{+0.4} \\
\hline $\mathrm{R} 16, \mathrm{R} 12$ & 12.5 & 0.50 & 0.89 & \multicolumn{2}{|l|}{-0.4} \\
\hline \multirow[t]{3}{*}{$\mathrm{R} 17, \mathbf{R} 11$} & 12.5 & 0.48 & 0.85 & \multicolumn{2}{|l|}{-0.4} \\
\hline & & & & \multicolumn{2}{|l|}{$\mathrm{C} 23$ (LGN) } \\
\hline & & & & \multicolumn{2}{|l|}{$q$} \\
\hline $\mathrm{C} 11, \mathrm{C} 10$ & 12.9 & 0.28 & 0.59 & \multicolumn{2}{|l|}{+1.0} \\
\hline $\mathrm{C} 10, \mathrm{C} 9$ & 13.2 & 0.81 & 1.47 & \multicolumn{2}{|l|}{-0.9} \\
\hline
\end{tabular}

Note: for cases $\mathrm{D}$ and $\mathrm{R}$ is the standard deviation of the $\mathrm{z}$-transformed $(\mathrm{Coh})^{1 / 2} \mathrm{~S} . \mathrm{D}$. $=0.10 ;$ a significant $(P<$ 0.01 ) effect of partialization is considered when $\Delta z>0.372$ S.D.; for case $C$ is the standard deviation of $\mathrm{z}(\mathrm{Coh})^{1 / 2}$ S.D. $=0.16$; in this case is $\Delta \mathrm{z}>0.527$ S.D. at $P<0.01 ;$ n.s. $=$ non-significant or $P>0.01$.

spectral frequency components have different sources and spatial distributions. In a small number of cases the effect of partialization was an increase in coherence value as indicated by a + sign in Table I. This occurred in those cases in which there was a large difference in coherence between the thalamic site and the two cortical sites of one pair, as follows: Coh $($ D20, D13 $)=0.40$ whereas Coh
$(\mathrm{D} 20, \mathrm{D} 11)=0.02 ; \mathrm{Coh}(\mathrm{R} 2, \mathrm{R} 19)=0.14$ whereas Coh $(\mathrm{R} 2, \mathrm{R} 18)=0.07$; Coh $(\mathrm{C} 23$, $\mathrm{C10})=0.28$ whereas Coh $(\mathrm{C} 23, \mathrm{C} 11)=0.04$. In these cases the effect of partialization was to eliminate what we may call a 'one-sided' thalamo-cortical component, i.e., a component which was not shared by both cortical sites, so that the remaining coherence between the 2 cortical sites increased. 
When a large coherence between two alpha rhythm signals is present or an appreciable effect of partialization is found, we can conclude that there are alpha rhythm components which are common to signals recorded from different sites. The question which in these cases must be answered is whether those common frequency components result from a passive process - volume conduction of the electrical potential - or whether they are determined by processes of active propagation of neural activity. In the former case the phase difference between the two signals should be zero; in the latter a phase which is significantly different from zero should be encountered. It is therefore of importance to examine the phase angles of those combinations of signals which presented large coherences and on which the effect of partialization was considerable (i.e., partial coherence decreased to a negligible value, $<0.10$ ).

We found that the pulvinar signal which was responsible for a large decrease in intracortical coherences after partialization presented a phase difference of $-101.5^{\circ} \pm 5^{\circ}$ in relation to $\mathrm{D} 17$ and $-68^{\circ} \pm 7^{\circ}$ in relation to D15; translated into the time domain these phase values correspond to, respectively, $21.1 \pm 2.1 \mathrm{msec}$ and $17.6 \pm 2 \mathrm{msec}$. It is interesting to relate these findings to the phase angle found between the LGN (C23) and the cortical site where the largest coherence $(0.56$ at $12.1 \mathrm{~Hz}$ ) was encountered: this was the combination $\mathrm{C} 23, \mathrm{C} 10$ with the last electrode situated in the marginal gyrus: the time delay computed in this case was $13 \pm 4 \mathrm{msec}$.

\section{Discussion}

The results of partial coherence analysis obtained by eliminating the influence of thalamic signals within the alpha frequency band, upon cortical areas, are clear in showing that a model based on point-to-point thalamo-cortical projections cannot be accepted to explain the organization of thalamo-cortical alpha rhythms. Therefore we conclude that a model based on multiple projections from a thalamic neuronal population to several cortical areas should be preferred. The projections could be realized either by way of ramifications of thalamo-cortical afferents or by way of intracortical projections. Of course, we have first to eliminate the possibility that the large effects of partialization might be due to spread of electrical potentials in the brain due to the passive process of volume conduction. We have demonstrated here that such a possibility cannot explain, by itself, our results since there are significant phase shifts between signals recorded from different cortical and thalamic sites. Similarly, we demonstrated previously that there are also significant phase shifts over the surface of the marginal gyrus (Lopes da Silva and Storm van Leeuwen 1978). Since alpha rhythms have been shown to originate in layers IV and $V$ of the visual cortex (Lopes da Silva and Storm van Leeuwen 1977, 1978) it has been hypothesized that in the cortex there exist 'epicentres' of alpha activity from which this activity spreads in different directions with relatively low 'apparent velocities of propagation', of the order of $0.3 \mathrm{~m} / \mathrm{sec}$.

The time delays measured between thalamic sites - pulvinar and LGN - and cortex are reported here for the first time; they correspond most certainly to the transmission of neural activity in the thalamo-cortical pathways. The difference between pulvinar- and LGN-cortical time delays indicate that, as regards the generation of alpha rhythms, the former correspond to slower pathways.

Another difference between pulvinar and LGN cortical relations was the much larger and more widespread influence of the former on cortico-cortical coherences within the alpha band. In particular, the pulvinar's influence was most pronounced on the mesial cortex neighbouring the marginal gyrus. This area corresponds in general terms to the area of projection of pulvinar afferents (mainly area 18) as studied in detail in other species than the dog (Garcy and Powell 1967; Ogren 1977). Histological analysis of the afferents of area 18 in squirrel monkeys led to the conclu- 
sion that there is, in this as in other cortical sensory areas, overlapping or interweaving of thalamic and cortical afferents (Curcio and Harting 1978); whether this is also the case in the dog is, of course, still a question. However, such a pattern of extensive overlapping of pulvinar-cortical afferents with intracortical connections would provide the structural basis which would explain the results obtained in the present investigation using partial coherence analysis.

Notwithstanding the effects of thalamic signals on cortico-cortical coherences it should be emphasized that the residual coherences measured between signals recorded over the mesial cortex were still very large. This implies that there must be other factors which are responsible for the large intracortical coherence. It is possible that there are thalamo-cortical afferents involved in the generation of the alpha rhythms which bifurcate and project to patches of cortex (Curcio and Harting 1978). However, it is not likely that such a system of bifurcation would be able to account for the large cortical areas over which coherent activity in the alpha band was encountered. Therefore, we consider more likely that an alternative may provide the substrate for explaining the present results. We consider as possible anatomical substrates the system of surface-parallel intracortical fibres which may extend over a distance of $6-8$ $\mathrm{mm}$, together with a pyramidal collateral spread module which extends over about 3 mm (Creutzfeldt 1978; Szentágothai 1978). This would also provide the structural basis for the spread of alpha activity from cortical epicentres over the surface of the cortex, as explained above. Theoretical investigations (Van Rotterdam et al. in preparation) indicate that this spread can be accounted for by a system of excitatory and inhibitory intracortical connections in which the influence of each neurone decays exponentially with distance, with a characteristic length of the order of a few hundreds of microns. Furthermore, the terminals of subcortical projections of different origins end up in overlapping cortical modules so that distinct, although neighbouring, cortical modules share common inputs. Indeed, if such a system did not exist we should be left with a patchy non-overlapping assembly of cortical modules, each with its own type of EEG activity, with little intracortical coherence; it would be almost impossible in such a case to record an EEG at a relative large distance from the cortex.

The present results have been obtained by way of a method which we may call a 'theoretical thalamic deafferentation'; the advantages offered by this signal analytical methodology over a real experimental deafferentation are certainly of importance, since in this way we can 'disconnect' brain areas one from the other without changing, by introducing lesions, the system which we want to study.

\section{Summary}

The thalamo-cortical relationships of alpha rhythms have been analysed in dogs using partial coherence function analysis. The objective was to clarify how far the large intracortical coherence commonly recorded between different cortical sites could depend on a common thalamic site. It was found that the alpha rhythm of the LGN influenced only moderately the coherence between cortical alpha rhythms whereas that of the pulvinar had much more influence, at least in relation to some cortical areas. Significant phase shifts between thalamus and cortex were also measured. The results demonstrate that there are thalamo-cortical and cortico-cortical components which interact in the generation of cortical alpha rhythms.

\section{Résumé}

Contributions relatives des processus intracorticaux et thalamo-corticaux dans la genèse des rythmes alpha, mises en évidence par l'analyse de cohérence partielle

Les relations entre le thalamus et le cortex pendant les rythmes alpha ont été analysées 
chez le chien en utilisant la méthode de l'analyse de cohérence partielle. Le but était de déterminer dans quelle mesure les valeurs élevées de la cohérence intra-corticale dépendent de l'activité d'une région déterminée et commune $d u$ thalamus. On a trouvé que tandis que l'influence du CGL était relativement faible, celle du pulvinar était beaucoup plus grande, au moins en ce qui concerne certaines aires corticales. Des relations de phase significatives entre le thalamus et le cortex ont également été mesurées. Ces résultats montrent qu'il existe des composantes thalamo-corticales et cortico-corticales qui interfèrent dans la genèse de l'activité alpha.

\section{References}

Creutzfeldt, O.D. The neocortical link: thoughts on the generality of structure and function of the neocortex. In: M.A.B. Brazier and H. Petsche (Eds.), Architectonics of the Cerebral Cortex, IBRO Monograph Series, Vol. 3. Raven Press, New York, 1978: 357-384.

Curcio, C.A. and Harting, J.K. Organization of pulvinar afferents to area 18 in the squirrel monkey: evidence of stripes. Brain Res., 1978, 143:155161.

Dixon, W.J. and Massey, Jr., F.J. Introduction to Statistical Analysis. McGraw-Hill, New York, 1957, $488 \mathrm{pp}$.

Garcy, L.J. and Powell, T.P.S. The projection of the lateral geniculate nucleus upon the cortex in the cat. Proc. roy. Soc. B, 1967, 167: 107-126.

Gersch, W. and Goddard, G.V. Epileptic focus location: spectral analysis method. Science, 1969, 970: 701-702

Lanoir, J. Etude électrocorticographique de la veille et du sommeil chez le chat. Organisation du cycle nycthéméral. Rôle du thalamus. Thèse Doct. Sci. Marseille. Centre régional de Recherche et de Documentation pédagogique, Marseille, 1972, 520 pp.

Lanoir, J. et Cordeau, J.P. Rythmes et fuseaux spontanés de l'aire visuelle du chat au cours des différents stades de la veille et du sommeil. J. Physiol. (Paris), 1970,62 (Suppl. 3): 399-400.

Lopes da Silva, F.H, and Storm van Leeuwen, W. The cortical source of the alpha rhythm. Neurosci. Lett., $1977,6: 237-241$.
Lopes da Silva, F.H. and Storm van Leeuwen, W. The cortical alpha rhythm in dog: depth and surface profile of phase. In: M.A.B. Brazier and H. Petsche (Eds.), Architectonics of the Cerebral Cortex, IBRO Monograph Series, Vol. 3. Raven Press, New York, 1978: 319-333.

Lopes da Silva, F.H., van Lierop, T.H.M.T., Schrijer, C.F. and Storm van Leeuwen, W. Organisation of thalamic and cortical alpha rhythms: spectra and coherences. Electroenceph. clin. Neurophysiol., 1973, 35: 627-639.

Lopes da Silva, F.H., Vos, J.E., Mooibroek, J. and Van Rotterdam, A. A partial coherence analysis of thalamic and cortical alpha rhythms in dog - a contribution towards a general model of the cortical organization of rhythmic activity. In: G. Pfurtscheller (Ed.), Event Related Changes in Cortical Rhythmic Activities - Behavioural Correlates. Elsevier/North-Holland Biomedical Press, Amsterdam, 1980: 33-59.

Ogren, M.P. Evidence for a projection from pulvinar to striate cortex in the squirrel monkey (Saimiri sciureus). Exp. Neurol., 1977, 54:622-625.

Rappelsberger, P., Petsche, H., Vollmer, R. and Lapins, R. Rhythmicity in seizure patterns - intracortical aspects. In: E.J. Speckmann and H. Caspers (Eds.), Origin of Cerebral Field Potentials. Thieme, Stuttgart, 1979: 80-97.

Rougeul, A., Corvisier, J. et Letalle, A. Rythmes électrocorticaux caractéristiques de l'installation du sommeil naturel chez le chat. Leurs rapports avec le comportement moteur. Electroenceph. clin. Neurophysiol., 1974, 37: 41-57.

Storm van Leeuwen, W. and Kamp, A. Radiotelemetry of EEG and other biological variables in man and dog. Proc. roy. Soc. Med. (Lond.), 1969, 62: $451-453$

Storm van Leeuwen, W., Kamp. A., Kok, M.L., De Quartel, F.W., Lopes da Silva, F.H. et Tielen, A.M. Relations entre les activités cérébrales du chien, son comportement et sa direction d'attention. Actualités neurophysiol., 1967, 7: 167-186.

Szentágothai, J. The local neuronal apparatus of the cerebral cortex. In: P. Buser and A. Rougeul-Buser (Eds.), Cerebral Correlates of Conscious Experience, INSERM, Symp. No. 6. Elsevier, Amsterdam, 1978: 131-138.

Vos, J.E., Lammertsma, A.A. and Van Eykeren, L.A. Ordinary and partial coherences of bipolar and quasi-unipolar derivations of infant electroencephalograms. In: K.R. Godfrey et al. (Eds.), Random Signal Analysis. IEEE Conference Publication No. 159, London, 1977: 154-160. 